International Journal of Medical Sciences

ISSN 1449-1907 www.medsci.org 2008 5(1):18-23

Research Paper

(C) Ivyspring International Publisher. All rights reserved

\title{
Plasmatic B-Type Natriuretic Peptide and C-Reactive Protein in Hyperacute Stroke as Markers of Ct-Evidence of Brain Edema
}

\author{
Pedro J Modrego', Beatriz Boned², Juan J Berlanga33, Mercedes Serrano³
}

1. Dept of Neurology. Miguel Servet University Hospital. Zaragoza. Spain

2. Biochemistry Unit. Hospital de Alcañiz. Spain

3. Neurology Unit. Hospital de Alcañiz. Spain

Correspondence to: Dr PJ Modrego, Dept of Neurology, Miguel Servet University Hospital, 50009 Zaragoza, Spain. E-mail: med009626@saludalia.com

Received: 2007.11.05; Accepted: 2008.01.08; Published: 2008.01.13

OBJECTIVE. Plasmatic B-type-natriuretic peptide (NT-PBNP) and C-reactive protein (CRP) have been reportedly elevated in stroke patients; however their clinical significance remains uncertain. The purpose of this work is to investigate whether elevation of these proteins at baseline predicts CT-evidence of brain edema.

METHODS. We recruited 41 consecutive patients with stroke and determined NT-PBNP and CRP at baseline (within 5 hours after onset), after 48-72 hours, and at discharge. Stroke severity was measured by means of the NIHS scale at baseline and at discharge. We also carried out brain CT at admittance and after 48 hours.

RESULTS. There were 29 ischemic strokes and 12 hemorrhagic strokes. Evidence of brain edema on delayed scan was seen in 14 patients. Baseline levels of NT-PBNP did not predict CT-evidence of edema but CRP levels did so significantly $(0.7 \mathrm{mg} / \mathrm{dl}$ in patients without edema versus $4.7 \mathrm{mg}$ in patients with edema; $\mathrm{p}=0.001)$. Both NT-PBNP and PC levels correlated poorly to NIHSS score and increased markedly from baseline to the second determination in patients with edema. For these patients the NT-PBNP increase was $133.6 \mathrm{pmol} / 1$ in comparison to $1.58 \mathrm{pmol} / 1$ in patients without edema $(\mathrm{p}=0.002)$. Neither CRP nor NT-PBNP baseline levels were predictive of dependency or death.

CONCLUSIONS. We conclude that CRP at baseline but not NT-PBNP predicts CT evidence of brain edema in stroke patients. We hypothesize that NT-PBNP levels elevated in response to edema after 48 hours of admission.

Key words: Stroke; Brain edema; C-reactive protein; B-type natriuretic peptide.

\section{INTRODUCTION}

Atrial natriuretic peptide (ANP) is released into circulation in response to atrial distention or sodium load. This counteracts the Renin-Angiotensin-Aldosterone system and causes an increase in the glomerular filtration rate with excretion of sodium and water. Brain natriuretic peptide (BNP) is released from the ventricular myocardium in response to elevation of ventricular diastolic pressure [1]. BNP is known to correlate with the presence and severity of congestive heart failure [2]. Usually it is determined the $\mathrm{N}$-terminal fragment (NT-pro-BNP) of the BNP. In the last years, the NT-pro-BNP levels in the serum have emerged as important predictor of mortality in stable coronary heart disease [3]. It has also bee regarded as predictor of mortality and cardiovascular events in older adults [4], as predictor of sudden death in patients with chronic heart failure [5], and as predictor of the risk of cardiovascular events and death in persons without heart failure [6]. BNP levels are also predictive of heart failure [7] and myocardial infarction [8] in patients with stroke or TIA. Furthermore, BNP levels are also predictive of ischemic stroke in patients with cerebrovascular disease beyond traditional risk factors [9].

C-reactive protein is a well-known marker of inflammation but the role as marker of atherothrombosis is currently being investigated. CRP was also related to increased mortality and cardiovascular events in older adults [4], to increased risk of heart failure in subjects with cerebrovascular disease [7], and to increased risk of stroke and TIA in the elderly [10].

ANP [11-13], BNP [13-15], and CRP [16-22] have been reported to be elevated in the acute phase of stroke but their clinical significance is mostly unknown. Brain edema is common in acute stroke and, many times, life-threatening. The reason for which malignant edema develops in some patients but does not in others is so far elusive. It becomes especially manifest after 48 hours from stroke onset. However on many occasions the edema is not seen until 48 hours or later from onset.

The main goal of this work is to find accurate 
baseline markers of delayed brain edema that might be helpful to anticipate the appropriate and early anti-edema measures. We hypothesize that plasmatic BNP and CRP values in hyperacute stroke might predict the development of CT-based evidence of delayed brain edema, and that these proteins increase in response to edema. The second objective of the study is to know whether the values of these proteins change according to clinical outcome.

\section{PATIENTS AND METHODS}

In this work we enrolled 48 patients with stroke in a consecutive manner. Stroke was defined as rapidly developing symptoms and signs of focal cerebral dysfunction lasting more than 24 hours with no apparent origin other than vascular. On admission we carried out general medical and neurological examination, blood pressure measurement, electrocardiogram, X-ray film of the chest, and brain Computed Tomography. Immediately a blood sample was drawn to determine ultrasensitive C-reactive protein and the N-terminal fraction (NT-PBNP) of the B-type natriuretic peptide within 5 hours after stroke onset. Serum NT-PBNP levels were measured by electrochemiluminiscence immunoassay on a Modular Analytics E170 analyzer (Roche Diagnostics). Ultrasensitive C-reactive protein (CRP-U) was measured by quantitative immunoturbidimetric assay on an Architect c-8000 analyzer (Abbot Diagnostics).

The normal NT-PBNP values in the serum for healthy people are below $30 \mathrm{pmol} / 1$ and those of CRP below $0.05 \mathrm{mg} / \mathrm{dL}$.

The stroke severity was measured by means of the National Institute of Health Stroke Scale (NIHSS). At 48 hours after admission we also carried out a new brain CT and determined again the CRP and NT-PBNP in the serum because the edema tends to be more evident after this elapse of time. By edema in ischemic stroke we mean mass-effect and sulcal effacement. For hemorrhagic stroke we mean the surrounding hypodensity of the hematoma with increased mass-effect in comparison to baseline scan. CT images were evaluated for the presence/absence of edema before knowing the levels of CRP and NT-PBNP.

At discharge we performed another determination of CRP and NT-PBNP in the serum, as well as new NIHS scale and the modified Rankin scale for assessing independence.

For statistical analysis we divided the patients into two groups: those who developed edema at 48 hours and those who did not. Comparisons were made with either $t$-Test or Mann-Whitney U-test in accordance with the presence/absence of normality in the distribution of the variables. We also analyzed correlation between stroke severity and the values of
CRP and NT-PBNP. The predictive values were analyzed by means of the ROC curves. A model of logistic regression was constructed to predict edema so as to control for potential confounders such as age, sex, atrial fibrillation, hypertension, diabetes, and hyperlipidemia. Operations were made with the SPSS software, version 10 (Chicago, IL).

This study was made with the informed consent of patients and/or relatives, and the authorization of the local review board as well.

\section{RESULTS}

Among the 48 patients recruited 4 were excluded because of congestive heart failure (signs of pulmonary edema on Rx film of the chest and/or reduced ventricular function on echocardiography) and 3 because of early death from ischemic stroke. The cause of early death was brain herniation in two patients, and heart failure in the other. The mean age of the patients excluded was 84.5 years; two were women and two were man. The four excluded patients showed very high levels of NT-PBNP (> $400 \mathrm{pmol} / \mathrm{L}$ ) as it is expected in patients with heart failure. The remaining 41patients underwent the complete protocol of the study. The mean age of the 41 patients was 78.3 years (range: 54-91). There were 26 men and 15 women. None of the patients included had history of congestive heart failure nor underwent thrombolysis. We neither saw patients with renal failure on the basis of plasmatic creatinine levels. In table 1 are reported the main baseline characteristics and risk factors.

Table 1. Main baseline characteristics and risk factors. $\mathrm{N}=41$

Mean age: 78.32 (SD: 6.77); range: 54-91

Sex: 26 male (634\%) and 15 female.

Mean temperature on admission : 36.6 0C (SD:0.4)

Mean systolic blood pressure on admission: 164.49 (25.36); range:

$107-220 \mathrm{~mm} \mathrm{Hg}$

History of hypertension: 21 (51.2\%).

Atrial fibrillation: 4 (9.75\%).

Diabetes mellitus: $9(22 \%)$

Hyperlipidemia: 7 (17\%)

Trasient ischemic attack : $9(21.9 \%)$

Coronary Heart Disease : 4 (9.75\%)

Tobacco habit: $3(7.3 \%)$

Obesity: 4 (9.75\%)

The type of stroke was ischemic in 29 patients and hemorrhagic of hypertensive cause in 12. Among ischemic strokes 6 were cardioembolic, 7 were lacunar, and the remainder (16) were ischemic non-cardioembolic (11 atherosclerotic and 5 of undetermined cause). The location of stroke was the anterior circulation in 30 patients and the posterior circulation in 11. The hemorrhagic stroke location was as follows: basal ganglia in 8 , lobar in 2, thalamic in one patient, and cerebellar in another one. 
On delayed CT 14 patients showed evidence of brain edema and 27 did not. The mean age for patients with edema was 80.29 years (SD: 4.16 ), and 77.3 (SD: 7.67) for those without edema (difference not significant). Among patients with edema 3 were female and 11 male. History of hypertension was positive in 5 patients $(35.7 \%)$ who showed edema and in $16(59.2 \%)$ of those without edema. The mean systolic/diastolic blood pressure at baseline for patients with edema was $166 / 80 \mathrm{~mm} \mathrm{Hg}$ in comparison to $163 / 77$ in those without edema. After 48 hours of stroke onset the blood pressure only elevated in 3 patients with edema (from 130/75 to 160/92; from $155 / 85$ to $170 / 95$; and from $165 / 90$ to $188 / 100$ ); in the remainder it was similar as at baseline. The mean NIHSS score on admission was 7.5 (SD: 6.18) and at discharge it was 5.94 (SD: 6.54). For patients with ischemic stroke the baseline NIHSS was 7.6 (SD: 5.4) and 7.3 (SD: 5.1) for those with hemorrhage. The mean NIHSS score for patients with edema was 11.77 (SD: 6.5) and for those without edema it was 5.5 (SD: 4.2), which was significant on $\mathrm{t}$-test $(\mathrm{p}=0.007)$.

The mean length of stay in hospital was 8.2 days (range: 3-30 days), and 5 patients died from stroke after having obtained the second blood sample for determinations of the proteins. The mean Rankin score at discharge was 2.14 (SD: 1.83) with 22 patients being independent. None of the patients included in the study had overt evidence of infection on admission on the basis of standard blood and urine tests, X-film of the chest and temperature controls.

In table 2 are presented the values of CRP and NT-PBNP of three determinations for all of the patients of the study. These values were increased in the three determinations in comparison to those of healthy people with the highest peak in the second determination. In table 3 are reported separately the same values for patients with edema and for those without edema. The 4 patients excluded because of congestive heart failure had very high levels of NT-PBNP (>400 pmol/l) and normal CRP values on admission.

Table 2. Mean values of CRP and NT-PBNP of the 41 patients

\begin{tabular}{|c|c|c|c|}
\hline VALUES & MEAN & SD & RANGE \\
\hline CRP-Baseline & 2.08 & 4.36 & $0.03-20.7 \mathrm{mg} / \mathrm{dl}$ \\
\hline CRP-48 hours & 3.94 & 6.4 & $0.09-26.13$ \\
\hline CRP-Discharge & 3.44 & 5 & $0.04-24.8$ \\
\hline & & & \\
\hline NT-PBNP-baseline & 103.1 & 169.7 & $2.8-672 \mathrm{pmol} / 1$ \\
\hline NT-PBNP-48 hours & 144.22 & 187.3 & $1.6-798.3$ \\
\hline NT-PBNP-Discharge & 111.8 & 171.55 & $1.58-736$ \\
\hline
\end{tabular}


comparison to those without edema (1.58 pmol/1); $\mathrm{p}=0.002$ on $\mathrm{t}$-test. See figure 3 .

In table 5 are presented the different values for ischemic and hemorrhagic stroke without significant differences. Ischemic strokes showed higher values of NT-PBNP and lower values of CRP than hemorrhagic strokes without statistical significance.

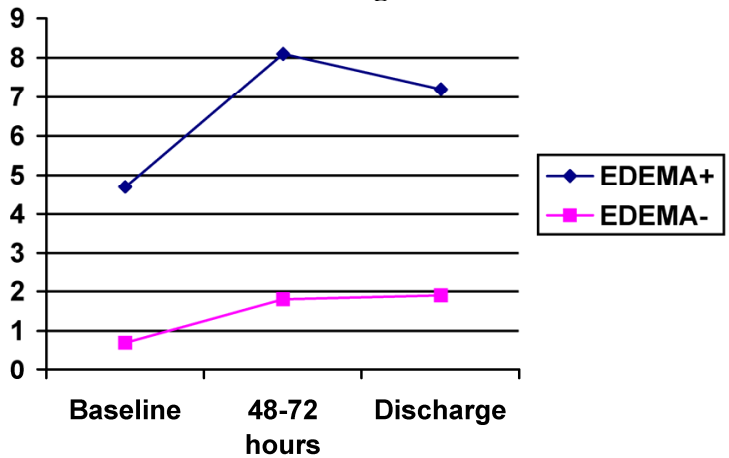

FIGURE 1. Graphic showing the mean values of plasmatic $\mathrm{C}$-reactive protein in three determinations.

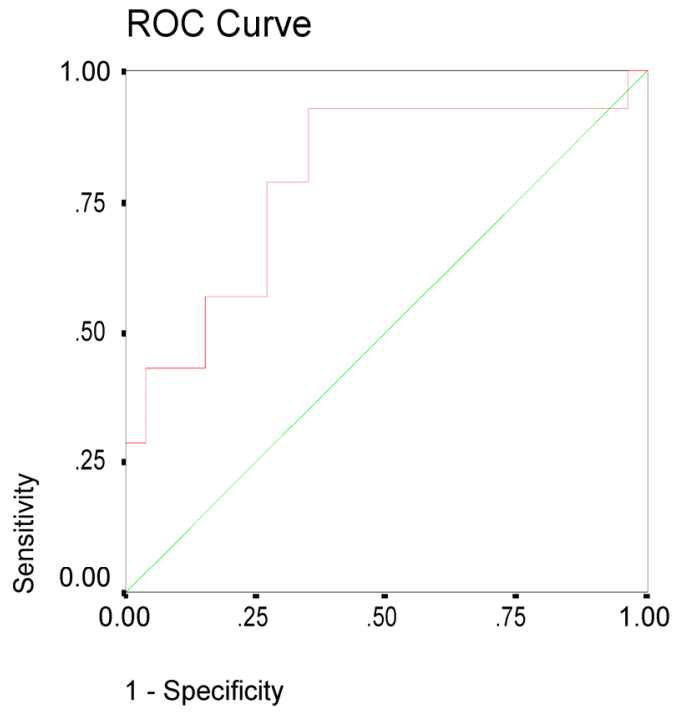

FIGURE 2. ROC curve of the CRP baseline values. Area under the curve: 0.8 (95\% CI: 0.64-0.95).

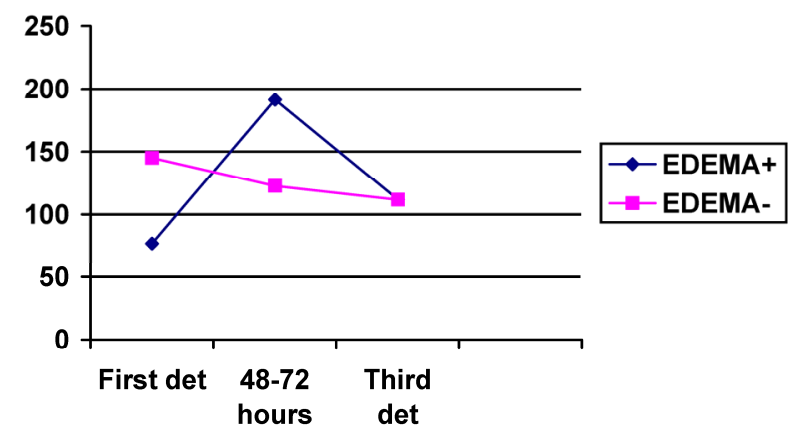

FIGURE 3. Graphic showing the mean values of NT-PBNP in three determinations. Vertical axis represents the values in $\mathrm{pmol} / 1$.
Table 4. Model of logistic regression. Dependent variable was brain edema.

\begin{tabular}{|c|c|c|c|c|}
\hline $\begin{array}{l}\text { Independent } \\
\text { variable }\end{array}$ & B & $\mathrm{T}$ & $\operatorname{Exp}(\mathrm{B})$ & Significance \\
\hline $\begin{array}{l}\text { Systolic } \\
\text { blood press. }\end{array}$ & 0.065 & 4 & 1.06 & 0.04 \\
\hline $\begin{array}{c}\text { CRP at } \\
\text { baseline }\end{array}$ & 1.66 & 4.5 & 5.27 & 0.03 \\
\hline Constant & -11.29 & 4.3 & 0.00 & 0.03 \\
\hline \multicolumn{5}{|l|}{$\begin{array}{l}\text { Variables not } \\
\text { in the } \\
\text { equation }\end{array}$} \\
\hline SEX & -0.16 & 0.02 & 0.84 & 0.8 \\
\hline AGE & 0.082 & 1.04 & 1.08 & 0.3 \\
\hline $\begin{array}{l}\text { History of } \\
\text { Hypertension }\end{array}$ & -1.19 & 1.75 & 0.0 & 0.18 \\
\hline $\begin{array}{l}\text { Diabetes } \\
\text { mellitus }\end{array}$ & -0.64 & 0.44 & 0.52 & 0.5 \\
\hline $\begin{array}{c}\text { Atrial } \\
\text { fibrillation }\end{array}$ & 6.1 & 0.03 & 0.002 & 0.8 \\
\hline
\end{tabular}

Table 5. CRP and NT-PBNP values for ischemic and hemorrhagic stroke.

\begin{tabular}{|c|c|c|c|}
\hline VALUES & $\begin{array}{c}\text { ISCHEMIC } \\
\text { STROKE } \\
(\mathrm{n}=29)\end{array}$ & $\begin{array}{c}\text { HEMORRHAGIC } \\
\text { STROKE }(\mathrm{n}=12)\end{array}$ & $\begin{array}{c}\text { P } \\
\text { VALUES }\end{array}$ \\
\hline CRP-Baseline & $1.16(1.71)$ & $4.3(7.36)$ & 0.17 \\
\hline CRP-48 hours & $2.56(3.73)$ & $7.16(9.8)$ & 0.14 \\
\hline CRP-Discharge & $2.51(2.76)$ & $5.78(8.15)$ & 0.24 \\
\hline NT-PBNP-Baseline & $\begin{array}{c}120.8 \\
(194.47)\end{array}$ & $61.61(81.3)$ & 0.09 \\
\hline NT-PBNP-48 hours & $\begin{array}{c}162.19 \\
(213.16)\end{array}$ & $102.3(101.17)$ & 0.23 \\
\hline NT-PBNP-Discharge & $\begin{array}{c}128.92 \\
(198.25)\end{array}$ & $69(59.39)$ & 0.18 \\
\hline
\end{tabular}

We did not find relationship between systolic blood pressure on admission and values of CRP and NT-PBNP. We neither found relationship between the baseline values of CRP and NT-PBNP and dependence at discharge or death. The mean baseline CRP level for independent patients at discharge (Rankin 0, 1, or 2) was 1.64 (SD: 4.4) in comparison to 2.78 (SD: 4.5) in those dependent (Rankin 3,4, or 5), which was not significant. The levels of NT-PBNP were neither related to age $(\mathrm{r}=0.23)$ or sex. Although women had higher mean baseline levels of NT-PBNP than men (117.75 pmol/L and 95.21 respectively), the difference was not statistically significant $(\mathrm{p}=.69)$.

Figure 4 represents and example of ischemic stroke and hemorrhagic stroke on baseline and delayed CT with edema developing after 48 hours. 


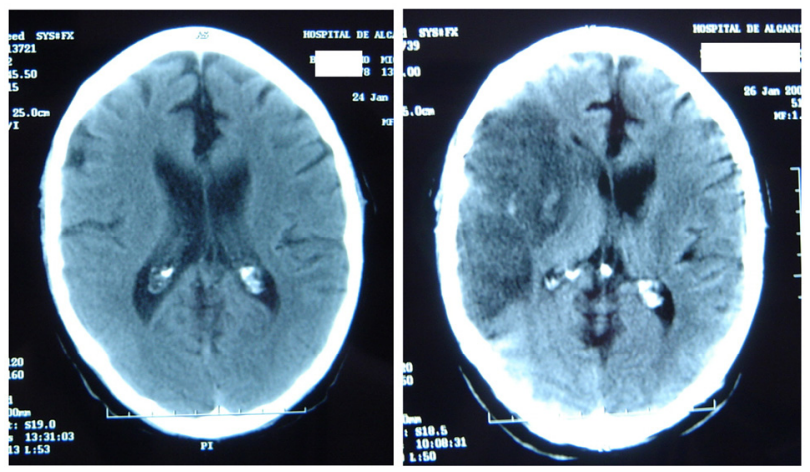

FIGURE 4. A. Ischemic stroke presenting with left hemiparesis. Normal CT on admission. CRP level: $6.9 \mathrm{~m} / \mathrm{dL}$; NT-PBNP level: 21pmol/L. B. CT scan after 48hours. Large infarction in the MCA territory showing mass-effect. CRP level: $7.9 \mathrm{mg} / \mathrm{dL}$; NT-PBNP level: $139 \mathrm{pmol} / \mathrm{L}$.

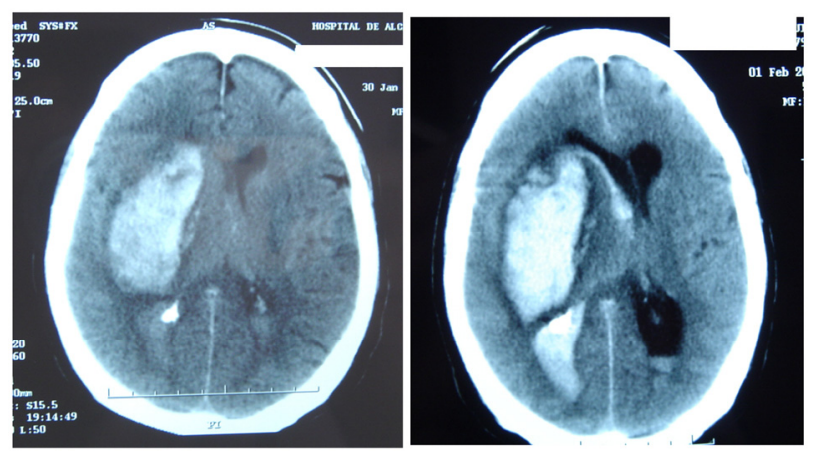

FIGURE 5. A. CT on admission. Hemorrhagic stroke presenting with headache and left hemiplegia. CRP level: 3.23 mg/dL. NT-PBNP level: 66.3 pmol/L. B. CT scan after 48 hours in the same patient. See the surrounding hypoatenuation of the hematoma with increased mass-effect. CRP level: 22.6. NT-PBNP level: $197 \mathrm{pmol} / \mathrm{L}$.

\section{DISCUSSION}

The role of CRP in inflammation and atherosclerosis has attracted the attention of many researchers but it is not clear whether CRP is only a marker or a causal factor [23]. This protein has been widely studied in the acute phase of ischemic stroke. Compared with controls CRP levels in the serum were higher than healthy controls in all stroke subtypes, in the acute phase and after 3-month follow-up [16]. The CRP levels correlated positively with the size of the infarct and stroke severity $[17,18]$. Furthermore CRP elevation in ischemic stroke indicates a worse prognosis, as it has been associated with higher in-hospital mortality $[9,20]$, higher mortality at 6 months [21], and more disability [22]. From the Perindopril Protection against Recurrent Stroke a case-control study showed that NT-PBNP levels but not CRP predicted stroke recurrence [9]. In this study we did not find prognostic significance of either CRP or NT-PBNP but we found relationship between the levels of these proteins and the size of the stroke lesion as edema tends to appear in large lesions. The lack of prognostic significance may be caused by the small sample size. Initially, one can speculate that the baseline CRP levels are related to the degree of carotid arteriosclerosis but two facts are against this hypothesis: the CRP levels were higher in hemorrhagic strokes, and that we found no differences of CRP levels between cardioembolic and atherosclerotic strokes.

The significance of NT-PBNP elevation in the acute phase of stroke is mostly unknown. In 86 consecutive patients with ischemic stroke the NT-PBNP levels were related to unfavorable outcome included death of any cause [24]. NT-PBNP levels in 250 patients at day 2 after ischemic stroke onset were predictive of 6-month mortality [25]. However another studies including 174 and 30 patients respectively with ischemic stroke concluded that NT-PBNP levels did not influence the clinical outcome [14,15]. The relationship between NT-PBNP levels and brain edema in the acute phase of stroke has been little investigated. Elevations of NT-PBNP were associated with hyponatremia and natriuresis in subarachnoid hemorrhage [26] as well as to hyponatremia and delayed vasospasm-related ischemic deficits [27]. Focal brain edema was related with elevations of ANP and BNP in 8 patients with subarachnoid hemorrhage [28]. In rodent model of subarachnoid hemorrhage the intraventricular administration of ANP reduced the sodium and water accumulation, as well as brain edema [29]. In rats with provoked-hemorrhagic stroke the intraperitoneal administration of ANP reduced water, sodium and edema 24 hours after the injury but mannitol did not so, which suggests that ANP could be used to treat brain edema [30]. The role of ANP in regulating blood flow in the infarcted area was studied in stroke patients and a statistically significant increase in the number of ANP-immunoreactive astrocytes was found in the white matter surrounding the infarction area [31].

We observed elevation of NT-PBNP in relation to brain edema in ischemic and hemorrhagic strokes as these levels showed the maximum peak after 48 hours from stroke onset. It is not likely that these elevations related with blood pressure elevations as it only occurred in 3 patients with edema. Our findings and those of the previous studies suggest that natriuretic peptides are produced in response to edema so as to reduce it. Whether or not the treatment with BNP may constitute an alternative of treatment in stroke-induced brain edema remains to be elucidated. The lack of efficacious treatment so far for stroke-induced brain edema makes our hypothesis 
worthy of consideration.

The most important shortcoming of our study was that edema was evaluated only with CT and, therefore, we focused only on severe edema. The practice of Diffusion weighted MRI would have added important information but unfortunately this technique was unavailable for us.

In conclusion, our work adds something new to the understanding of the elevation of CRP and NT-PBNP in the acute phase of stroke. both CRP and NT-PBNP are markers of brain edema in stroke at baseline and after 48 hours respectively. Given that brain edema may be a life-threatening condition, anti-edema measures could be anticipated in hyperacute stroke in patients with high baseline levels of ultrasensitive C-reactive protein. Owing to the small sample size of our study these results need to be confirmed in larger samples of stroke patients.

\section{CONFLICT OF INTEREST}

The authors have declared that no conflict of interest exists.

\section{REFERENCES}

1. Edema BE. In: Fauci AS, et al, eds. Harrison's principles of Internal Medicine, 14th ed. McGraw-Hill: New York. 1998: 210-214.

2. Strunk A, Bhalla V, Clopton P, et al. Impact of the history of congestive heart failure on the utlity of B-Type natriuretic peptide in the emergency diagnosis of heart failure: results from the Breathing Not Properly Multinational Study. Am J Med. 2006; 119: 69e1-69e11.

3. Kragelund C, Gronning B, Kober L, Hildebrandt P, Steffensen R. N-terminal pro-B-Type Natriuretic Peptide and long-term mortality in stable coronary heart disease. N Engl J Med. 2005; 352: 666-675.

4. Kistorp C, Raymond I, Pedersen F, Gustafsson F, Faber J, Hildebrandt P. N-terminal pro-brain natriuretic peptide, C-reactive protein, and urinary albumin levels as predictors of mortality and cardiovascular events in older adults. JAMA. 2005; 293: 1609-1616.

5. Berger R, Huelsman M, Strecker K, et al. B-type natriuretic peptide predicts sudden death in patients with chronic heart failure. Circulation. 2002; 105: 2392-2397.

6. Wang TJ, Larson MG, Levy D, et al. Plasma natriuretic peptide levels and the risk of cardiovascular events and death. N Engl J Med. 2004; 350: 655-663.

7. Campbell DJ, Woodward M, Chalmers JP, et al. Prediction of heart failure by amino terminal-pro-B-type natriuretic peptide and C-reactive protein in subjects with cerebrovascular disease. Hypertension. 2005; 45: 69-74.

8. Campbell DJ, Woodward M, Chalmers JP, et al. Prediction of myocardial infarction by $\mathrm{N}$-terminal-pro-B-type natriuretic peptide, C-reactive protein, and renin in subjects with cerebrovascular disease. Circulation. 2005; 112: 110-116.

9. Campbell DJ, Woodward M, Chalmers JP, et al. Soluble vascular cell adhesion molecule 1 and $\mathrm{N}$-terminal pro-B-type natriuretic peptide in predicting ischemic stroke in patients with cerebrovascular disease. Arch Neurol. 2006; 63: 60-65.

10. Rost NS, Wolf PA, Kase CS, et al. Plasma concentration of C-reactive protein and risk of ischemic stroke and transient ischemic attack: the Framingham study. Stroke. 2001; 32: 2575-2579.
11. Estrada V, Tellez MJ, Moya J, Fernandez-Durango R, Egido J, Fernández-Cruz AF. High plasma levels of endothelin-1 and atrial natriuretic peptide in patients with acute ischemic stroke. Am J Hypertens. 1994; 7: 1085-1089.

12. Sato Y, Maruoka H, Honda Y, Hachiya N, Oizumi K. Plasma concentration of atrial natriuretic peptide in cardioembolic stroke with atrial fibrillation. Kurume Med J. 1995; 42: 71-77.

13. Makikallio AM, Makikallio TH, Korpelainen JT, et al. Natriuretic peptides and mortality after stroke. Stroke 2005; 36: 1016-1020.

14. Etgen T, Baum H, Sander K, Sander D. Cardiac troponins and $\mathrm{N}$-terminal pro-brain natriuretic peptide in acute ischemic stroke do not relate to clinical prognosis. Stroke. 2005; 36: 270-275.

15. Giannakoulas G, Hatzitolios A, Karvounis H, et al. N-terminal pro-brain natriuretic peptide levels are elevated in patients with acute ischemic stroke. Angiology. 2005; 56: 723-730.

16. Ladenvall C, Jood K, Blomstrand C, Nilsson S, Jern C, Ladenvall $\mathrm{P}$. Serum C-reactive protein concentration and genotype in relation to ischemic stroke subtype. Stroke. 2006; 37: 2018-2023.

17. Audeberg HJ, Rott MM, Eck T, Haberl RL. Systemic inflammatory response depends on initial stroke severity but is attenuated by successful thrombolysis. Stroke. 2004; 35: 2128-2133.

18. Marquardt L, Ruf A, Mansmann U, Winter R, Buggle F, Kallenberg K, Grau AJ. Inflammatory response after acute ischemic stroke. J Neurol Sci. 2005; 236: 65-71.

19. Masotti L, Ceccarelli E, Forconi S, Cappelli R. Prognostic role of C-reactive protein in very old patients with acute ischemic stroke. J Intern Med. 2005; 258: 145-152.

20. Rallidis LS, Vikelis M, Panagiotakos DB, et al. Inflammatory markers and in-hospital mortality in acute ischemic stroke. Atherosclerosis. 2005.

21. Kocer A, Canbulat C, Gozke E, Ilhan A. C-reactive protein is an indicator for fatal outcomes in first-time stroke patients. Med Sci Monit. 2005; 11: CR540-544.

22. Arevalo-Lorido JC, Carretero-Gomez J, Calvo-Romero JM, et al. $\mathrm{C}$-reactive protein in the acute phase of ischemic stroke. Med Clin (Barc). 2005; 125: 775-777.

23. Paffen E, DeMaat MP. C-reactive protein in atherosclerosis: A causal factor? Cardiovasc Res. 2006; 71: 30-39.

24. Yip HK, Sun CK, Chang LT, Chen MC, Liou CW. Time course and prognostic value of plasma levels of $\mathrm{N}$-terminal pro-brain natriuretic peptide in patients after ischemic stroke. Circ J. 2006; 70: 447-452.

25. Jensen JK, Mickley H, Bak S, Korsholm L, Kristensen SR. Serial measurements of $\mathrm{N}$-terminal pro-brain natriuretic peptide alter acute ischemic stroke. Cerebrovasc Dis 2006; 22:439-444

26. Tomida M, Muraki M, Uemura K, Yamasaki K. Olasma concentrations of brain natriuretic peptide in patients with subarachnoid hemorrhage. Stroke. 1998; 29: 1584-1587.

27. McGirt MJ, Blessing R, Nimjee SM, et al. Correlation of serum brain natriuretic peptide with hyponatremia and delayed ischemic neurological deficits after subarachnoid hemorrhage. Neurosurgery. 2004; 54: 1369-1373.

28. Fukui S, Nawashiro H, Otani N, et al. Focal brain edema and natriuretic peptides in patients with subarachnoid hemorrhage. Acta Neurochir (Wien). 2003; 86: 489-491.

29. Doczi TP, Joo F, Balas I. Atrial natriuretic peptide (ANP) attenuates brain edema accompanying experimental subarachnoid hemorrhage. Acta Neurochir (Wien). 1995; 132: 87-91.

30. Rosenberg GA, Estrada EY. Atrial natriuretic peptide blocks hemorrhagic brain edema after 4-hour delay in rats. Stroke. 1995; 26: 874-877.

31. Nogami M, Shiga J, Takatsu A, Endo N, Ishiyama I. Immunohistochemistry of atrial natriuretic peptide in brain infarction. Histochem J. 2001; 33: 87-90. 